\title{
Impact of branding social responsibility on the memory of consumers using brain waves analysis
}

\author{
Davoud Sadeh', Hamidreza Saeednia ${ }^{2 *}$ (iD, Peter Steidl ${ }^{3}$, Kambiz Heidarzadeh ${ }^{4}$ \\ 1. PhD Student, Department of Business Management, Qazvin Branch, Islamic Azad University, Qazvin, Iran \\ 2. Associate Professor, Department of Business Management, North Tehran Branch, Islamic Azad University, Tehran, Iran \\ 3. $\mathrm{PhD}$, Department of Business Management, Vienna University, Vienna, Austria \\ 4. Associate Professor, Department of Business Management, Science and Research Branch, Islamic Azad University, Tehran, Iran
}

Recieved: 4 Apr. 2018

Revised: 20 Jun. 2018

Accepted: 19 Jul. 2018

\section{Keywords}

Branding social responsibility (BSR)

EEG

Memory

Theta wave

\section{Corresponding author}

Hamidreza Saeednia, Associate Professor, Department of Business management, North Tehran Branch, Islamic Azad University, Tehran, Iran

Email: Dr.saeednia1@gmail.com

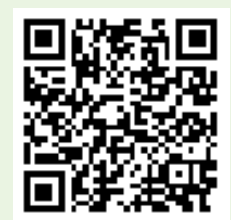

doi.org/10.30699/icss.21.2.74

\section{Abstract}

Introduction: On the basis of the scientific evidence illustrating that emotions dominate the cognitive and behavioral processes. Emotions are required to be taken into account in advertising because the advertisement of branding social responsibility for organizations can be considered an emotional potential for promotion and a competitive strategic.. Methods: The research was an exploratory-laboratory method. In order to record brain signals, the Electroencephalography instrument using through the EEG EPOC + 14 Electrode wireless device was applied. After clearing the signals using Emotive 3D Brain Visualizer, the frequency band and its position were extracted. The statistical population of the study consisted of two groups of 25 people (examination and control), which is a stimulus in the form of advertising for the examination group with a social nature and for the control group with a completely economic nature.

Results: Three-dimensional analysis of the brain in terms of brain wave production showed that the examination group had a significant frequency with respect to the nature of the high-frequency stimulus in the theta wave; also, the results of ANOVA confirm this. Conclusion: The results indicated that branding social responsibility could be effective in terms of its impact on the brain on brand reminders. This finding confirms previous studies that theta frequency band can affect memory if it exists. 


\title{
تاثير مسئوليت اجتماعى برند بر روى حافظه مصرفكنندكان با تحليل امواج مغزى
}

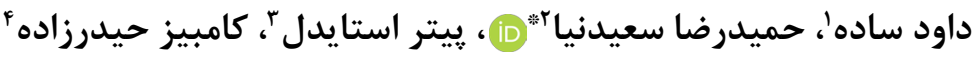

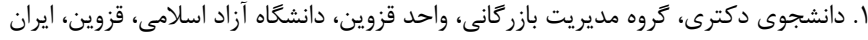

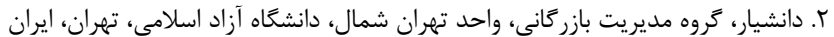

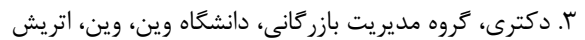

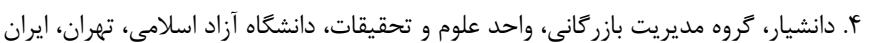

\section{aris}

مقلدمه: بر اساس شواهد علمى مبنى بر اين كه احساسات در فرايندهاى شناختى و رفتارى غالب هستند. احساسات بايد در تبليغات مورد توجه قرار گيرند زيرا تبليغات مسئوليت اجتماعى برند براى سازمانها مى تواند پتانسيلى احساسى براى ارتقاء و يك استراتزى رقابتى تلقى كردد.

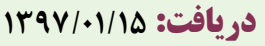

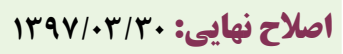

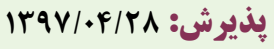
وازهنهاى كليدى روش كار: روش تحقيق از نوع اكتشافى_ آزمايشًاهى بود. از ابزار الكتروانسفالوكرافى براى ثبت سيحنال هاى مغزى از طريق دستكاه EEG EPOC+14 Electrode wireless استفاده گَرديد و پِ از پِاكسازى سيكنال ها با استفاده از نرم افزار Emotiv 3D Brain Visualizer، شدت باند فركانسى و موقعيت آن استخراج كرديد. جامعه آمارى تحقيق را دو كروه هr نفره (آزمايش و كنترل) تشكيل دادند كه محرك در قالب تبليغ براى كروه كنترل با ماهيت اجتماعى و براى كروه آزمايش با ماهيت كاملا اقتصادى ارايه شد. يافته ها: تحليل سه بعدى مغز با توجه به توليد امواج مغزى نشان داد كه بصورت معنادارى گروه كنترل با توجه به ماهيت محرك شدت فركانس بالا را در موج تتا داشتهاند كه نتايج تجزيه و تحليل واريانس نيز اين معنادارى را تاييد مى كند. نتيجه گَيرى: نتايج نشان داد مسئوليت اجتماعى برند مى تواند با توجه به تاثير آن بر روى مغز بر روى يادآورى يك برند موثر باشد. اين يافته تحقيقات كذشته را مبنى بر اينكه باند فركانسى تتا در صورت وجود مى تواند بر روى حافظه تاثير بخذارد را تاييد مى كند.

مقلدمه

Wundt بسيارى از محققان توجه خود را بر ساخت احساسات متمركز كردند. نويسندكان مهرم، همانند ويليام جيمز، نظريههاى هيجانات را بيشنمهاد دادند و تلاش كردند تا اين ساختار را عملى كنند. تا به امروز، موضوع مههم احساسات، عمدتا مسئله اندازهخيرى است (V).
بر اساس شواهد علمى مبنى بر اينكه احساسات در فرايندهاى شناختى و رفتارى غالب هستند، احساسات بايد در تبليغات مورد توجه قرار گيرند (1). به طور خاص، پاسخ عاطفى به يك تبليغ مى تواند بر جندين جنبه از جمله نخرش نسبت به تبليغات و برند (r، ؟) و در نهايت حفظ پيام و همجنين مطلوبيت آن تاثير كذارد (1 -9). در سال WV9 


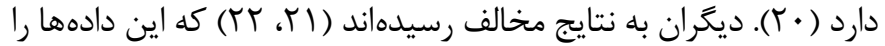
به عنوان يك اثر بومرنگ توصيف شده در تئورى واكنش روانشناختى

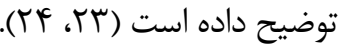

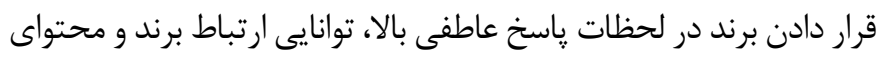

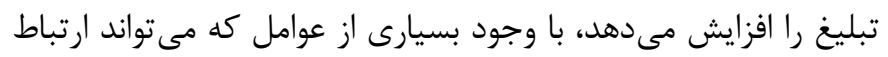

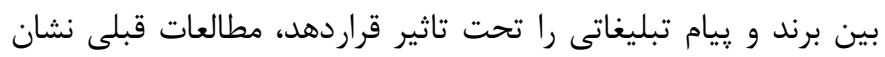
داده است كه عوامل اجرايى و يردازش براى ايجاد جنين ارتباطى ترجيح داده مىشوند. به عنوان مثال برخى از نظريهها مانند مدل شبكه حافظه ييشنهاد كردهاند كه تغييرات در ظاهر برند در طول يك تبليغات در واقع مىتواند ارتباط بين آكهى و برند را تحت تاثير قرار دهد. علاوه بر اين، تحقيقات نوروفيزيولوزيكى نشان مىدهد كه حافظه را مىتوان با استفاده از زمينه-هاى احساسى در زمان رمزگذارى تحريك نمود (Tه)

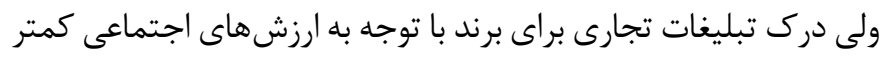

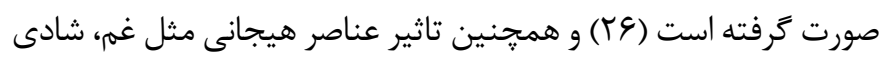
و تعجب و ... بر روى حافظه اثبات شده است (TV) ولى ماهيت بوجود آورنده اين عناصر مدنظر قرار نكرفته كه در يزوهش حاضر عناصر هيجانى به واسطه مسئوليت اجتماعى مورد بررسى قرار كرفتهاند. در توضيح مسئوليت اجتماعى برند مىتوان كفت بر اساس مدل شبكه تلفيقى

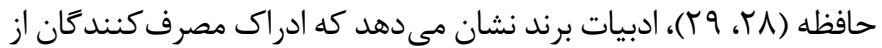
برندها بر اساس يك شبكه روانى از پِيوستخى هاى برند مبتنى است (•r-

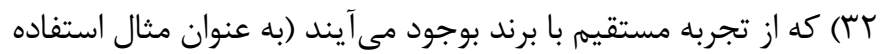

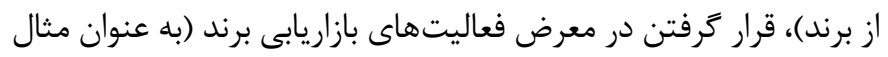

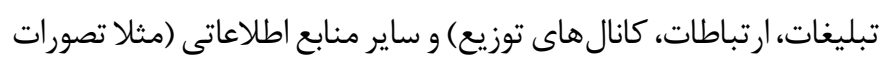

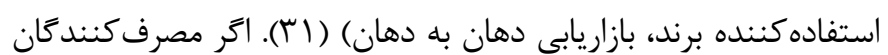
اطلاعاتى ناقص در مورد يك برند داشته باشند، ممكن است بر مبناى نتيجه كيرىهاى ناشى از تجربه قبلى بر اساس نامهاى تجارى باشد (سبس،

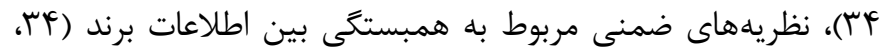

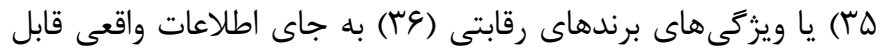
مشاهده و گم شده است. اين نشان مىدهد كه وابستخى هاى برند حتى

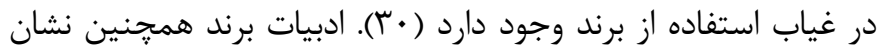

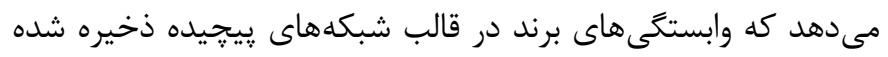

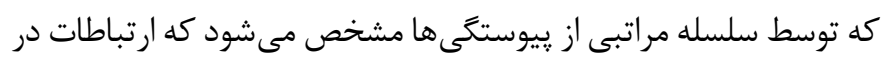

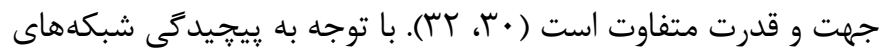
ذهنى وابسته، ادراكات مصرفكننده، جمعآورى راحتتر قابل بازيابى از وابستكى هاى ذخيره شده را به جاى بازتعريف دقيق شبكه به يك إنى

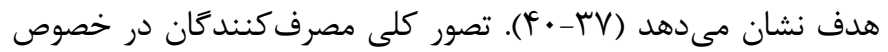

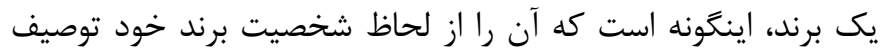

تكنيكهاى سنتى تحقيق، به روشهايى كه مىتوانند به عنوان "خود كزارش احساسات براى رسيدن به اهداف مىباشد را آزمايش كنند، زيرا آنها

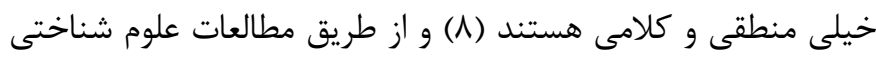

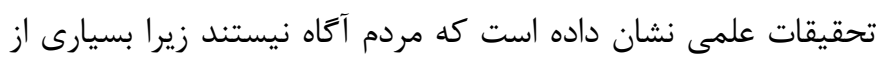

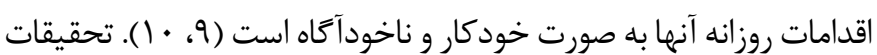
همجنين نشان داده است كه جَكونه احساسات مىتوانند بدون آكاهى افراد رفتار كنند، به همين دليل، روشهاى مبتنى بر ادراى عاطفى ذهنى هميشه قادر به ضبط دقيق حالت احساسى فرد نيستند. در مقابل،

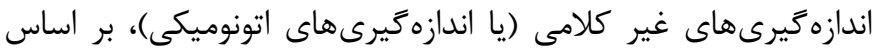
ثبت نوروفيزيولوزيك يارامترها، خروجى دقيقتر و قابل اطمينان را ارائه

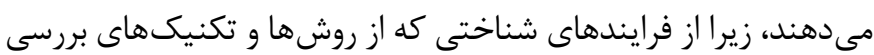
سنتى فعال مى شوند، استفاده نمى كنند (1).

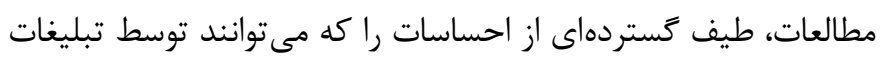

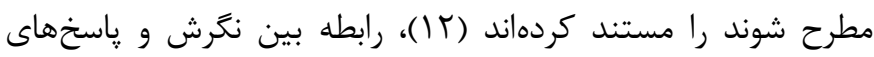

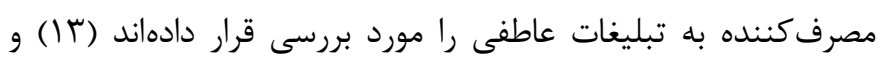
تفاوتهاى فردى يا متغيرهاى موقعيتى را مورد بررسى قرار دادند كه اغلب ياسخ هاى مصرف كننده به تجربيات عاطفى القاشده توسط تبليغات مىباشد. با اين حال، تحقيقات مصرف كننده عمدتا در مورد جزئيات شناختى احساسات سكوت كرده است. به نظر مىرسد اين به دليل فرض كسترداى است كه حساسيت يك احساس در يك تبليغ (مثلا مثبت

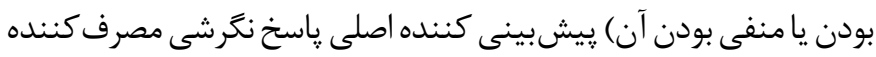

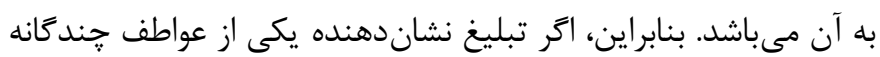
باشد كه همه يك احساس مشترك را در خود دارند (مثلا احساسات

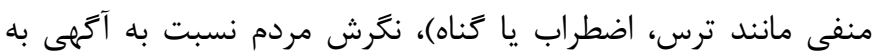
سادگى منعكس كننده آن است (مثلا منفى). با اين حال، داستان گويى با لا تجربيات عاطفى (مثبت يا منفى) به عنوان يكى از موثرترين استراتزىها براى تشويق رفتار طرفدار اجتماعى است (If). كميِين هاى اجتماعى اغلب احساسات منفى را به عنوان ترس ايجاد مى كنند. اين يك تاكتيك

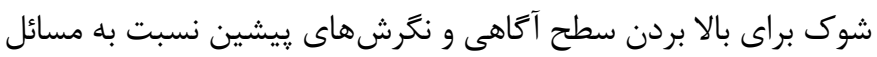

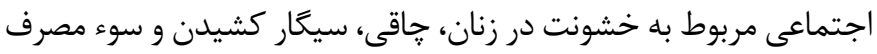

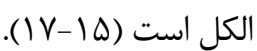
ادبيات نشان داده است كه نتايج متناقضى در مورد مطالعاتى وجود دارد كه داستان منفى و مثبت را مقايسه مى كند. بعضى از نويسندكان دريافتند كه استفاده از ترس و شوك در كمبينهای بازاريابى تاثير مثبتى

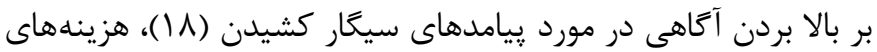
اجتماعى مصرف نوشابههاى كازدار (19) و اثرات زيانبار سوءمصرف مواد 
مولفههاى مستقل (Independent component analysis) با Emotiv 3D تميز شد. سيس، با استفاده از نرم افزار EEGLAB Brain Visualizer

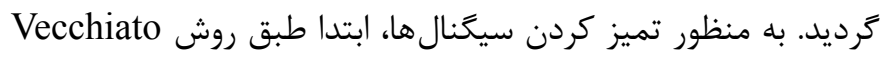

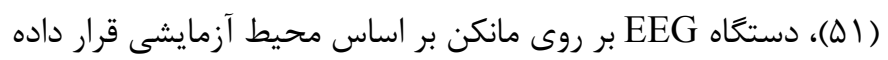

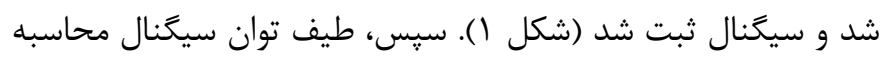

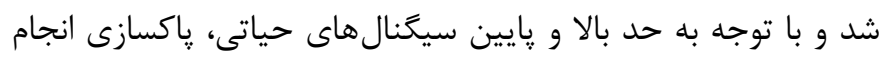

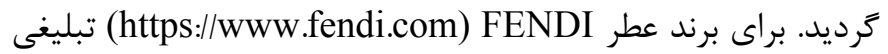
با مسئوليت اجتماعى كه شعارهاى اجتماعى را از طريق كفتار ترويج مى داد و تبلينى ديكر با ماهيت مطلق اقتصادى ايجاد شد. ينجاه نفر آزمايش شدند حجم نمونه با توجه به نظر اكثر محققان عصب پايه

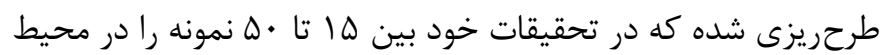

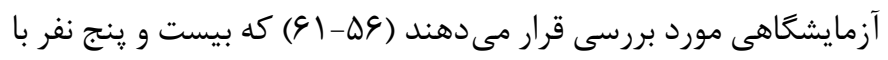
اين عطر در سه مرحله با ماهيت اجتماعى و بيست و ينج نفر باقيمانده

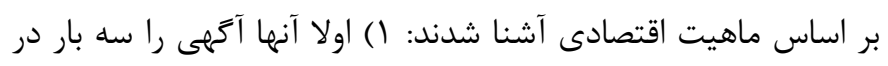

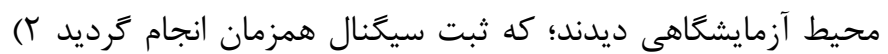
همجنين براى شركت كنندَان، يك محيط روابط عمومى ايجاد كرديد

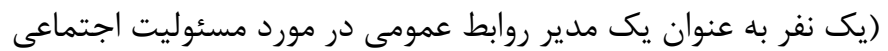

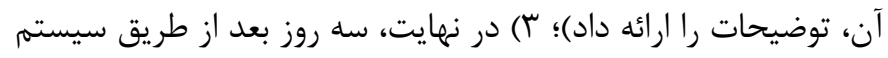
تلكرام براى افراد، تبليغات جايى برند مربوطه با شعار اجتماعى ارسال

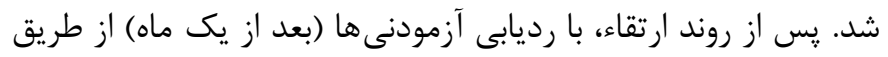

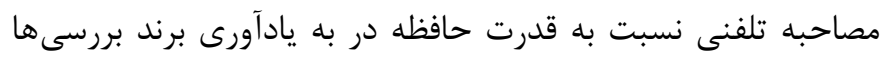

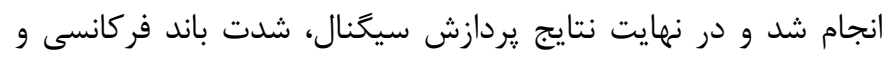

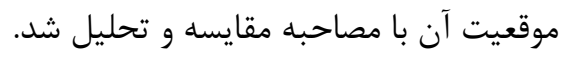

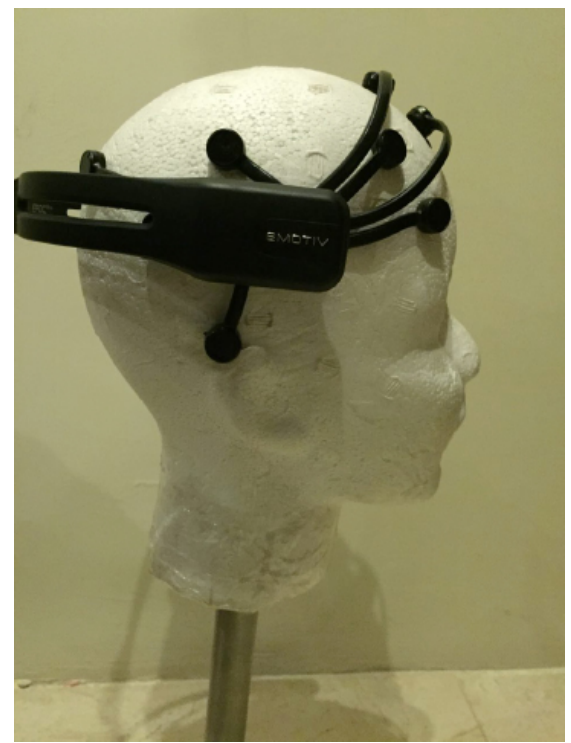

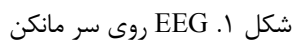

يا خصوصيات انسانى را ارزشمند كند ابراز مى كنند (أf، זF). اين نوع

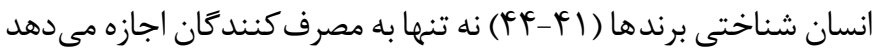

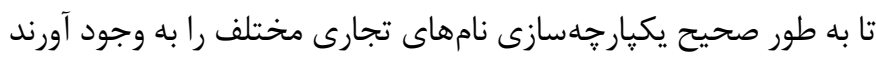
(أl)، بلكه باعث مىشود كه مصرفكنندكان نسبت به برند مربوط بهات

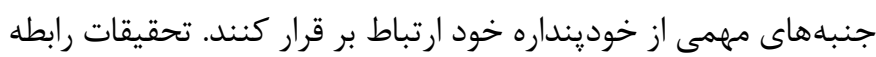

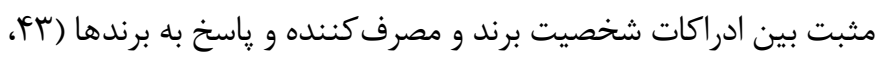

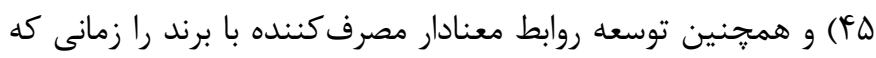

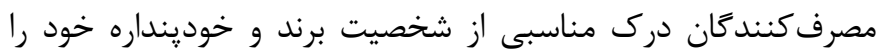

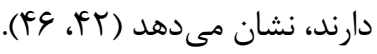
با Electroencephalogram (EEG) مى توان امواج مغز و حالات

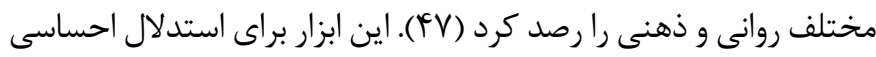

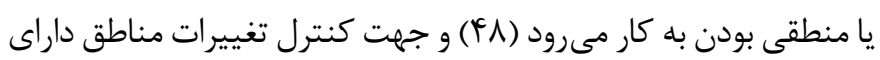

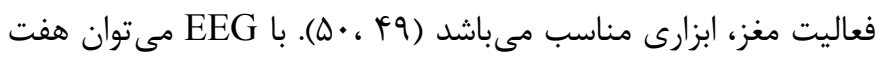

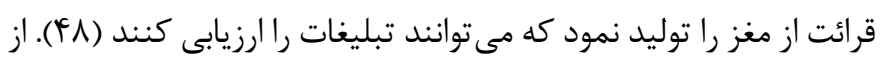

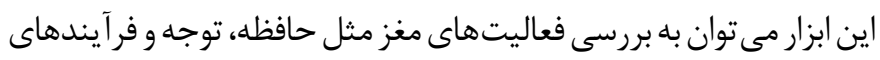

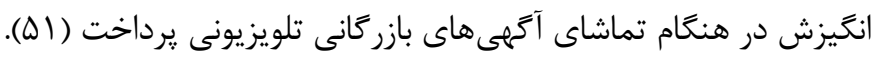
EEG به روشهاى سنتى مثل مصاحبه و يرسشنامه نتيجه بهترى دارد (UI).

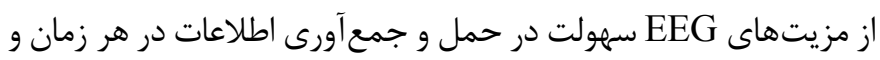

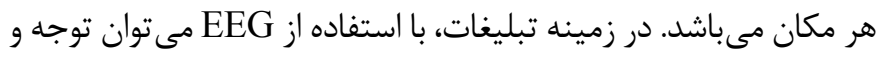

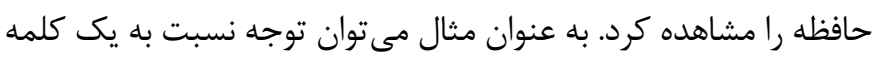

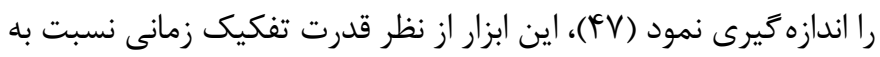

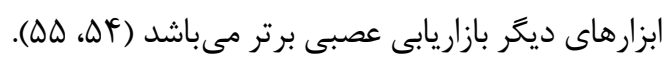

\section{روش كار}

در اين يزوهش از يك دستخاه EMG EPOC استفاده شده است كه در صنايع بازى به كار كرفته مى شود.

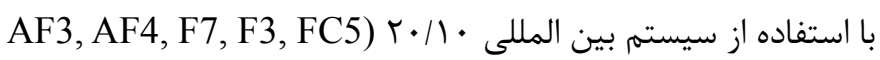
(T7, P7, O1, O2, P8, T8, FC6, F4, F8 استفاده از يك سيستم الكترودهاى خشك بر اساس سنسورهاى محلول نمك واقع در يوست سر، با مراجع CMS/DRL در مكان هاى P3/P4

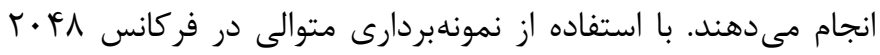
هرتز و يايين نمونه به 1 ا هرتز استفاده مى شود. اين دستخاه شبيه

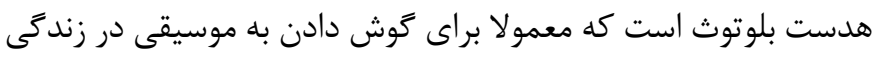
روزمره استفاده مى شود. دادههاى جمع آورى شده توسط EEG با استفاده از تجزيه و تحليل 
كافته ها

جدول ا براى هر دو كروه ثبت باند فركانسى موج تتا را در حالت بالاترين و يايين ترين حد نشان مىدهد كه در طول تبليغ با مشاهده ثبت كرديده است و براى بررسى معنادارى از آزمون آناليز واريانس استفاده شده است (جدول r) كه عامل معنادارى تاييد مى كند بين

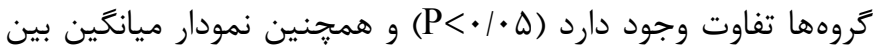
كروهها (نمودار () اين تفاوت را محسوس نشان مى دهد.

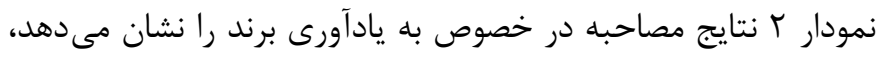

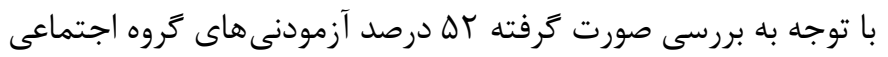

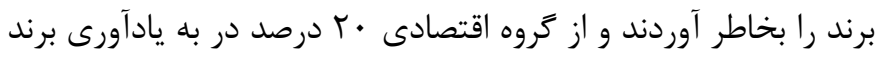

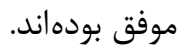

شكل r نمونه خروجى تحليل سه بعدى امواج مغزى را نشان مى دهد كه رنكَها به ترتيب بنفش (صورتى) امواج تتا، امواج نارنجى دلتا، بنفش التش (سايهدار) امواج بتا و امواج زرد آلفا مىباشد. با توجه به نتايج بدست آمده بر اساس باند فركانسى كه در جدول الرايه شده است و همجنين يردازش تصوير در خصوص رنت بنفش (امواج تتا) در راستاى تئورى

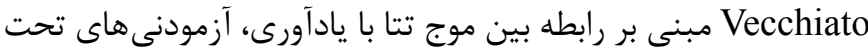

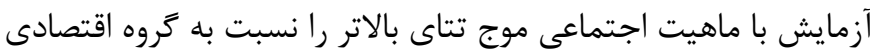

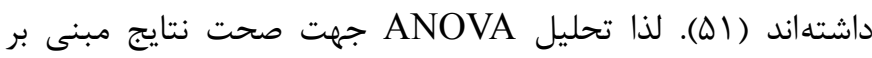
تفكيك دو كروه انجام شد و در نهايت نتايج مطالعات عصبى با مصاحبه

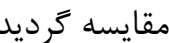
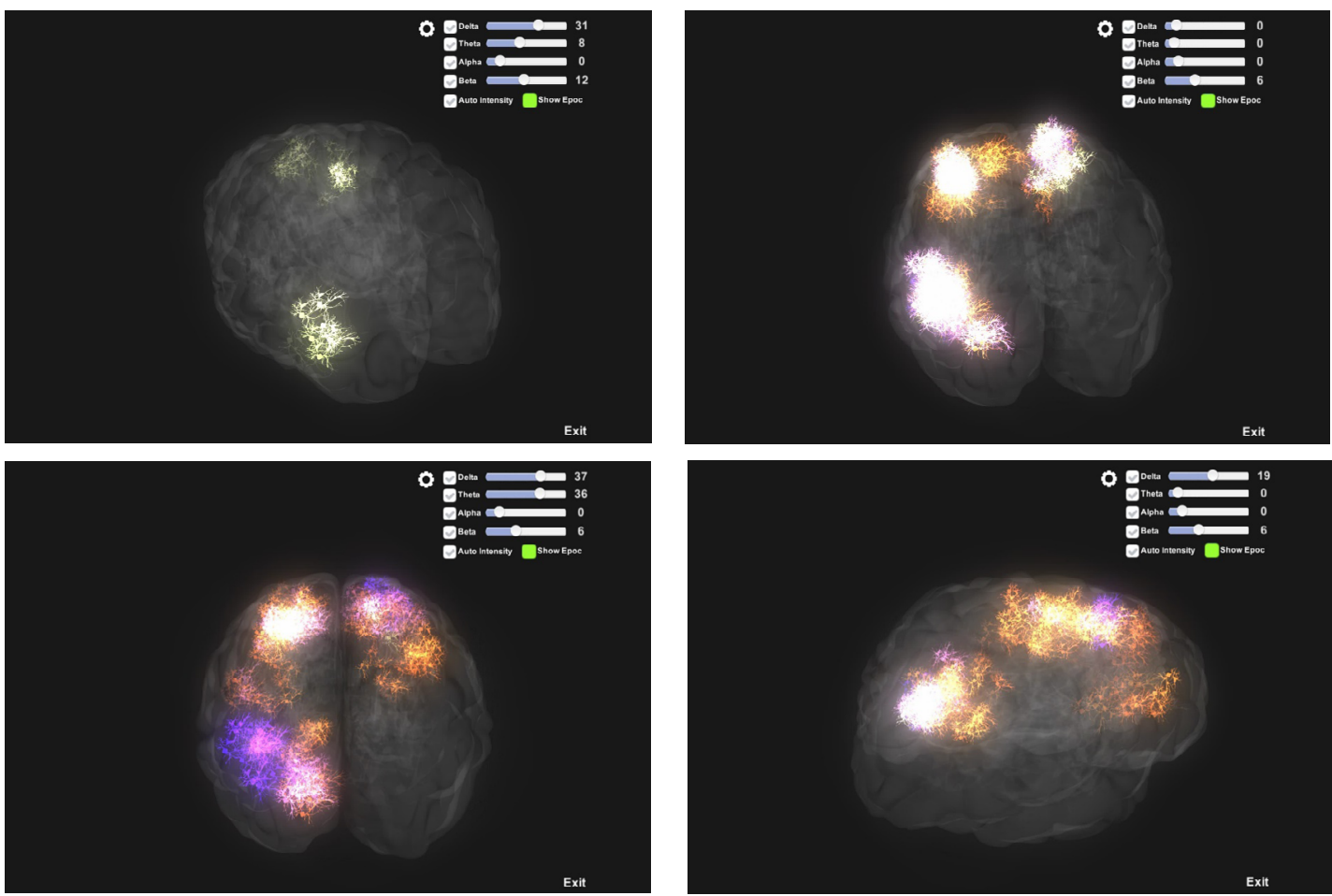

شكل r. نمونه نتايج سه بعدى امواج مغزى با رصد كردن موقعيت و نوع امواج مغزى

جدول ا. نتايج باند فركانسى امواج تتا

\section{نمونهها}

\begin{tabular}{|c|c|c|c|c|c|c|c|c|c|c|c|c|c|c|c|c|c|c|c|c|c|c|c|c|c|c|c|}
\hline TQ & TF & $r$ & Tr & rI & $r$. & 19 & 11 & IV & 19 & 10 & if & ir & ir & 11 & 1. & 9 & $\wedge$ & v & 9 & $\Delta$ & f & $r$ & r & 1 & \multicolumn{3}{|c|}{ موج تتا } \\
\hline re & re & rV & rV & rq & rq & ry & ry & ro & $r v$ & rr & rq & rı & rv & rq & rt & ru & il & rq & ra & re & rı & ו & rq & rv & حد بالا & $\overline{:}$ & \\
\hline 1 & r & r & 1 & $\Delta$ & . & 1 & $r$ & v & r & . & 1 & 1. & $r$ & $\Delta$ & $\Delta$ & v & Ir & 9 & r & 9 & r & 1. & v & 11 & حد بايين & y & 12 \\
\hline r & 19 & r) & rI & $r$. & rI & 19 & 11 & rr & 19 & 11 & $r$. & rI & r & ro & rq & TF & 11 & $r$ & ro & rq & ri & TT & TF & ro & حد بالا & $\overline{7}$ & \\
\hline . & . & . & . & . & . & . & . & . & . & . & . & . & . & & • & $\cdot$ & & & & & & & & & & 3 & \\
\hline
\end{tabular}


جدول r. نتايج تجزيه و تحليل واريانس

\begin{tabular}{|c|c|c|c|c|c|}
\hline $\mathbf{P}$ & $\mathbf{F}$ & ميانگين مربعات & درجه آزادى & مجموع مربعات & \\
\hline \multirow{2}{*}{$\cdot 1 \cdots$} & \multirow{2}{*}{$\cdots / 09$} & $\cdots / \mid f \cdot r$ & 1 & $\cdots / \mid f \cdot r$ & بين كروهها \\
\hline & & $\cdots / r \mu$ & $\psi_{\lambda}$ & $\cdots / 11 r r$ & درون گروهها \\
\hline 1 & & & pq & $\cdots / r \Delta r \wedge$ & كل \\
\hline
\end{tabular}
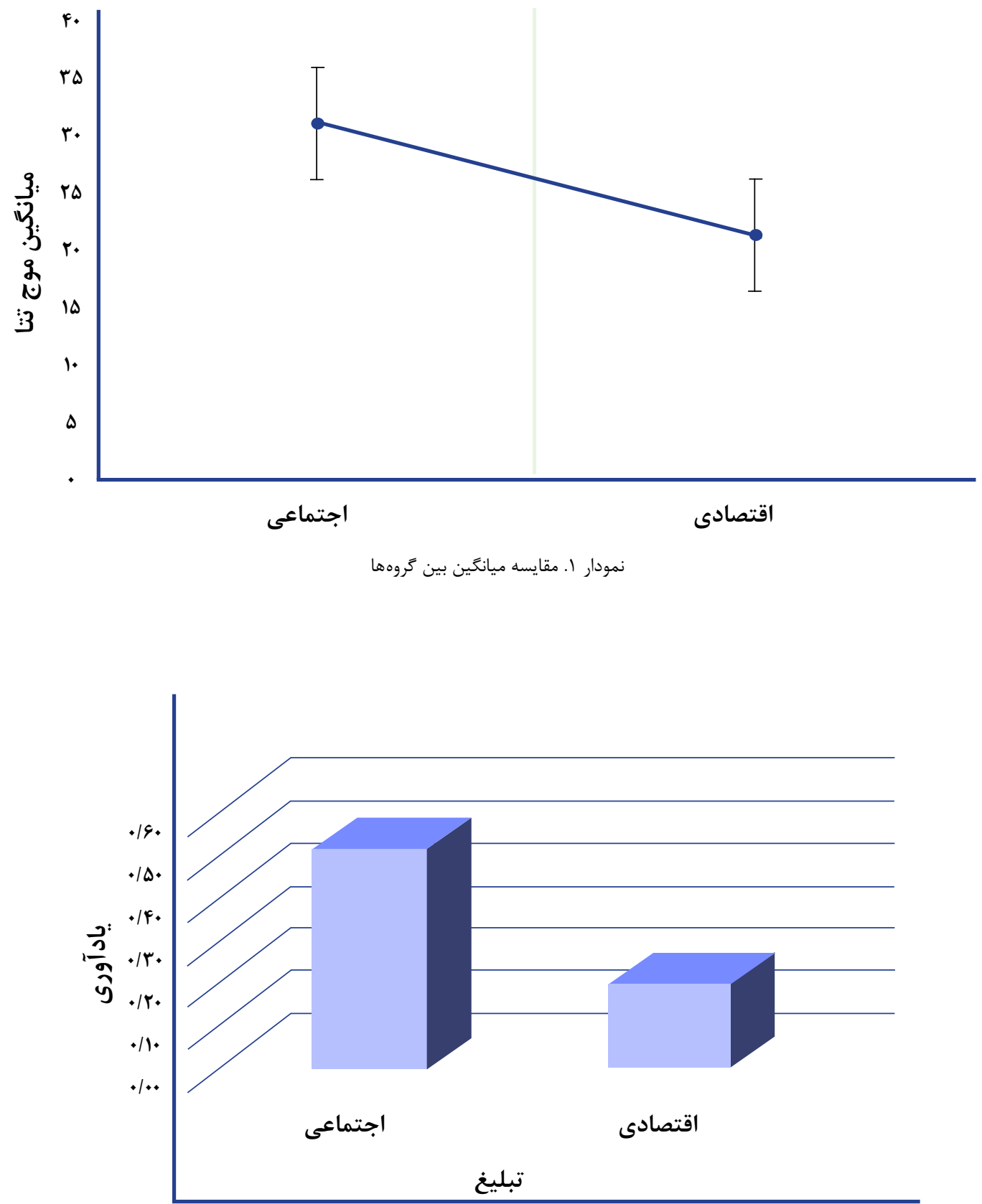

نمودار r. وضعيت به يادآورى برند در كروههاى كنترل و آزمايش 
ماهيت تبليغات مسئوليت اجتماعى برند با توجه به عناصر هيجانى به غمگينى نزديك مىباشد كه در مطالعه Wan Ismail و همكاران (GT) رابطه معنادارى بين موج تتا با حالت هيجانى غمگًينى اثبات شده است.

\section{زتنيجه كيمى} مى توان نتيجه گرفت كه مسئوليت اجتماعى برند مىتواند با توجه به تاثير عصبى در توليد موج تتا قدرت يادگيرى و حافظه را تقويت نموده و در برندينَ عصب يايه به عنوان يك رويكرد استراتزيك براى سازمانها تلقى گردد.

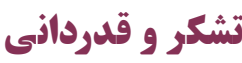

مقاله حاضر بخشى از رساله دوره دكترى تخصصى يزوهش محور مديريت بازاريابى در دانشگاه آزاد اسلامى قزوين مىباشد. نويسندگًان بر خود لازم مى دانند مراتب تشكر صميمانه خود را از مسئولان دانشكده و مركز تخصصى بازاريابى عصبى وانان تهران كه ما را در انجام و ارتقاء كيفى اين يزوهش يارى دادند، اعلام نمايند.

\section{References}

1. American Psychiatric Association, 2013. Diagnostic and Statistical Manual of Mental Disorders 5th Edition:DSM-5®. American Psychiatric Pub, Arlington VA.

2. Rahimian Boogar E, Sadeghi A. Prevalence of reading disorder in primary school students. Iranian Journal of Psychiatry and Clinical Psychology. 2007;12(4):396-402. (Persian)

3. Jorm AF. The cognitive and neurological basis of developmental dyslexia: A theoretical framework and review. Cognition. 1979;7(1):19-33.

4. Lara AH, Wallis JD. The role of prefrontal cortex in working memory: A mini review. Frontiers in Systems Neuroscience. 2015;9:173

5. Baddeley A. Working memory. Current Biology. 2010;20(4):136-140.

6. Baddeley AD. Logie. RH. Working memory: The multiple-component model. In Miyake A \& Shah P, editors. Mod els of working memory: Mechanisms of active maintenance
انجام تبليغات با ماهيت اجتماعى نشان داد كه ذهن مصرف كنندگان را مى توان نسبت به نام و برند درگير كرد. هر جقدر طرح و پيام و شعار از طراحى خوب با توجه به روح انسانى برخوردار باشد بر ادراك و حافظه مصرف كنندكان تاثير بيشترى را خواهد كذاشت. هماهنكى و هارمونى بين طرح و شعار صحت بالا را بدنبال خواهد داشت. مطالعات عصب رب رئ يايه مىتواند يك ابزار توانمند براى بازاريابان به منظور صحه كذارى بـ روش هاى ترويج و برندينَ تلقى شود. مطالعات Vecchiato و همكاران مبنى بر تاثير توان طيفى موج تتا بر روى حافظه در اين يزوهش نيز تاييد گرديد با اين تفاوت كه به عنوان يك يافته مهرم عنصر مسئوليت اجتماعى برند (BSR) باعث بالا بردن و توليد موج تتا مىشود، البته

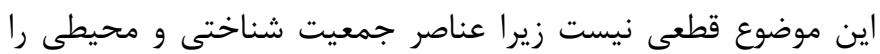
نمى توان از آن فاكتور گرفت لذا با در نظر گرفتن گروههاى كنترل و آزمايش مى توان اين تئورى را مطرح نمود ( اله). با توجه به يتانسيل بالاى تبليغات اجتماعى در ايجاد هيجان مىتوان استنباط كرد كه يادكيرى افزايش بيدا كرده و اين دليلى بر طيف بالاى موج تتا مىباشد كه در تحقيق Missaglia و همكاران (V) مشهود بوده است و همجنين يُنين

and executive control. New York:Cambridge University Press;1999. (pp. 28-61)

7. Alloway TP, Gathercole SE, Adams AM, Willis C. Working memory abilities in children with special educational needs. Educational and Child Psychology. 2005;22(4):56-67.

8. McLean JF, Hitch GJ. Working memory impairments in children with specific arithmetic learning difficulties. Journal of Experimental Child Psychology. 1999;74(3):240-260.

9. Andersson U, Lyxell B. Working memory deficit in children with mathematical difficulties: A general or specific deficit? Journal of Experimental Child Psychology. 2007;96(3):197-228. 10. Bull R, Scerif G. Executive functioning as a predictor of children's mathematics ability: Inhibition, switching, and working memory. Developmental Neuropsychology. 2001;19(3):273-293.

11. Gathercole SE, Alloway TP, Willis C, Adams AM. Working memory in children with reading disabilities. Journal of Exper- 
imental Child Psychology. 2006;93(3):265-281.

12. Dahlin KI. Effects of working memory training on reading in children with special needs. Reading and Writing. 2011;24(4):479-491.

13. Martinussen R, Hayden J, Hogg-Johnson S, Tannock R. A meta-analysis of working memory impairments in children with attention-deficit/hyperactivity disorder. Journal of the American Academy of Child \& Adolescent Psychiatry. 2005;44(4):377-484.

14. Martinussen R, Tannock R. Working memory impairments in children with attention-deficit hyperactivity disorder with and without comorbid language learning disorders. Journal of Clinical and Experimental Neuropsychology. 2006;28(7):10731094.

15. Weismer SE, Evans J, Hesketh LJ. An examination of verbal working memory capacity in children with specific language impairment. Journal of Speech, Language, and Hearing Research. 1999;42(5):1249-1260.

16. Baddeley AD, Hitch G. Working memory. Psychology of Learning and Motivation. 1974;8:47-89.

17. Peng P, Barnes M, Wang C, Wang W, Li S, Swanson HL, et al. A meta-analysis on the relation between reading and working memory. Psychological Bulletin. 2018;144(1):48-76.

18. Vandenbroucke L, Verschueren K, Desoete A, Aunio P, Ghesquière P, Baeyens D. Crossing the bridge to elementary school: The development of children's working memory components in relation to teacher-student relationships and academic achievement. Early Childhood Research Quarterly. 2018;42:1-10.

19. Fletcher JM. Classification and identification of learning disabilities. In: Wong B, Butler DL, editors. Learning about Learning Disabilities. 4th ed. Massachusetts:Academic Press;2012. pp. 1-25.

20. Kamyabi M, Teimory S, Mashhadi A. The effectiveness of working memory training on decreasing reading problems and improving working memory in dyslexic students. Exceptional Education. 2014;2 (124):33-41. (Persian)
21. Meltzer L. Executive function in education: From theory to practice. 2nd ed. New York:Guilford Press;2018.

22. Mirmehdi SR, Alizadeh H, Seif Naraghi M. The impact of training executive functions on mathematics and reading performance in primary students with specific learning disabilities. Journal of Exceptional Children. 2009:9(1):1-12. (Persian)

23. Klingberg T, Fernell E, Olesen PJ, Johnson M, Gustafsson P, Dahlström K, et al. Computerized training of working memory in children with ADHD-a randomized, controlled trial. Journal of the American Academy of Child \& Adolescent Psychiatry. 2005;44(2):177-186.

24. Klingberg T, Forssberg H, Westerberg H. Training of working memory in children with ADHD. Journal of Clinical and Experimental Neuropsychology. 2002;24(6):781-791.

25. Hossein Khanzadeh AA, Azadimanesh P, Mohammadi H, Ahmadi S, Sadeghi S. The effectiveness of programs to strengthen working memory and visual perception on improving reading students with reading disorder. Quarterly Journal of Psychological Studies. 2016;12(2):49-66. (Persian)

26. Soleimani Z, Dastjerdi KM. Determination of the validity and reliability of phonological awareness test. Journal of Psychology. 2005;9(1):82-100. (Persian)

27. Rahmani J, Abedi MR. Color Raven standardized test for children 5 to 10 years old in Isfahan. Journal of Quarterly Teachings. 2004;23:81-86. (Persian)

28. Shahim S. Adaptation and standardization of the Wechsler Intelligence Scale for Children. Journal of Social Sciences and Humanities of Shiraz University. 1992;7(1-2):123-154. (Persian)

29. Azizian M, Abedi MR. Construction and standardization of reading level diagnostic test for third grade primary school children. Iranian Journal of Psychiatry and Clinical Psychology. 2006;11(4):379-387. (Persian)

30. Karimi B, Alizadeh H. Spelling learning Disorder (Assessment and Instruction). Tehran:Ravan:2013. (Persian)

31. Tabrizi M. Treatment of reading disorders. Tehran:Fararavan;2013. (Persian) 
32. Sangary MR, Alizadeh FS. Reading Instruction (Reading Method). 16th ed. Tehran:Aboata;2015. (Persian)

33. Hallahan DP, Lloyd JW, Kauffman JM, Weiss MP, Martinez EA. Learning disabilities: Foundations, characteristics, and effective teaching. 3rd ed. Boston:Pearson. 2004.

34. Safapour A. Secondary school Persian language skills training strategies: For teachers, educators, and students of educational centers. Tehran:Research and Educational Planning Organization;2000. (Persian)

35. Hsu LS, Ip KI, Arredondo MM, Tardif T, Kovelman I. Simultaneous acquisition of English and Chinese impacts children's reliance on vocabulary, morphological and phonological awareness for reading in English. International journal of Bilingual Education and Bilingualism. 2019;22(2):207-223.

36. Kjeldsen AC, Kärnä A, Niemi P, Olofsson Å, Witting K.
Gains from training in phonological awareness in kindergarten predict reading comprehension in grade 9. Scientific Studies of Reading. 2014;18(6):452-467.

37. Park J, Ritter M, Lombardino LJ, Wiseheart R, Sherman S. Phonological awareness intervention for verbal working memory skills in school-age children with specific language impairment and concomitant word reading difficulties. International Journal of Research Studies in Language Learning. 2014;3(4):3-22.

38. Dahlin E, Neely AS, Larsson A, Bäckman L, Nyberg L. Transfer of learning after updating training mediated by the striatum. Science. 2008;320(5882):1510-1512.

39. Baddeley A, Gathercole S, Papagno C. The phonological loop as a language learning device. Psychological Review. 1998;105(1):158-173. 